\title{
Legal ignorance and optimal standards of negligence
}

\author{
Lando, Henrik
}

Document Version

Final published version

Publication date:

2006

\section{License \\ CC BY-NC-ND}

Citation for published version (APA):

Lando, H. (2006). Legal ignorance and optimal standards of negligence.

Link to publication in CBS Research Portal

\section{General rights}

Copyright and moral rights for the publications made accessible in the public portal are retained by the authors and/or other copyright owners and it is a condition of accessing publications that users recognise and abide by the legal requirements associated with these rights.

Take down policy

If you believe that this document breaches copyright please contact us (research.lib@cbs.dk) providing details, and we will remove access to the work immediately and investigate your claim. 


\section{Legal ignorance and optimal standards of negligence}

Henrik Lando ${ }^{1}$

Copenhagen Business School and LEFIC

Abstract

How should a court set the negligence standard in a given area of activity when future (potential) injurers or victims are unlikely to know the standard set by the court? In particular, how should the standard be set in the oftoccurring case where one of the future parties is a professional actor who is likely to know the legal standard of negligence, while the other is an amateur, who is unlikely to know it? In this case, it may be optimal for the court to set the standards at the first-best level despite the amateur's ignorance of the law. The amateur may be able to infer the standards, either from the situation itself (from his knowledge of the costs and benefits of precautions), or from the act

${ }^{1}$ Henrik Lando, Professor of Law and Economics, Copenhagen Business School and LEFIC,

Kilevej 14a, 3d., 2000 Frederiksberg, Denmark. Phone: 4538152531. Fax:

4538152540.e-mail: hl.ivs@cbs.dk 
performed by the professional party. Moreover, the amateur may take due care because he realizes that the professional party will have an incentive to live up to the standard, and that the risk of a loss will therefore be on the amateur. However, when the ignorance of the amateur is 'large', involving not only the legal standards but also the risks inherent in the activity, it may well be optimal for the court to depart from first best standards.

JEL: K10, K13, K14

Key words: negligence standards, legal ignorance

Introduction

In deciding a case where a group of defrauded amateur investors sued a bank for not having warned them, the Court ${ }^{2}$ considered which signals to send to the parties. On the one hand, the Court wished to instruct future amateur investors that they must seek professional advice. On the other hand, it felt that banks should warn its customers when losses could thereby be prevented at low cost to the bank. According to the standard law and economic analysis

2 The Danish Supreme Court, U.2000.577/2H. 
of tort and contract/tort boundary law, when deciding whether to hold the bank negligent, a court should consider the relative costs and benefits of care by the parties. This article stresses that the court should also take into account which of the two parties is more likely to receive the signal. In the example, future amateur investors would seem less likely to receive the signal than banks; while the latter are long-run players in the market, for whom it may well be cost-justified to become informed about legal standards, the future amateur investor may be less likely to invest in information concerning legal rules. The point here is not that the amateur will be uncertain about the legal standards; this issue has been explored in the law and economics literature already (e.g. by Craswell and Calfee (1986) and Shavell (1987)). Rather, it is that the probability distribution that an uninformed party forms of the standard set by the court may ${ }^{3}$ be independent of the actual standard. If so, the standard set by the court may not affect the behavior of the amateur. In analyzing the consequences of one-sided legal ignorance, I will assume that the amateur knows less not only about the standard set by the court but potentially also about the risks involved. The professional actor will be assumed to operate many times under similar circumstances, and to become aware of risks over time, while the amateur is assumed as a one-time player to be less likely to know the risk. In part of the analysis, the amateur will be

\footnotetext{
${ }^{3}$ Notwithstanding the point made below that the amateur may under some circumstances be able to infer the standard.
} 
assumed to know the risk (this will be modeled as the amateur knowing which 'game' is being played) while in part it will be assumed that the amateur does not know the probabilistic consequences of his or her acts.

Within this general framework, it is not clear whether one-sided legal ignorance should lead courts to set standards other than the first best, or whether it should raise or lower standards applied to the professional party. In favor of maintaining first best standards, it may be argued that if the ignorant party is rational, he or she should realize that the other side has an incentive to live up to the standard of negligence in order to escape liability. The amateur should realize that if the professional party is the injurer and acts with due care, the loss will fall on the amateur. If the amateur realizes this, he or she may take due care despite of being ignorant of the legal standard, and the court should then set standards at first-best levels. Naturally, this logic assumes that the amateur understands the situation and the risks involved. He or she may realize that the risk will be his or her but may not know the size of the risk and may hence not act with due care. Again, however, it may be counter-argued that the amateur can sometimes infer the size of the risk from the act taken by the professional. If e.g. the professional party exercises care, and this is evident to the amateur, the amateur should be aware that there exists a risk, and should infer that the professional party will not be liable in the event of a loss, etc. Below, it will be argued that while it is indeed conceivable that the amateur can infer the risk from the act of the professional, when the latter acts first, and while the negligence rule is 
conducive to this kind of signaling by discouraging the professional from attempting to delude the amateur, it is easy to conceive of situations where the act by the professional does not contain enough information for the amateur to know the risk. Thus, it may e.g. not be clear to the amateur when observing the absence of care by the professional, whether this means that there is no risk or whether it only means that the professional is the cheaper cost avoider (and that the standard of care for the professional is not to take care).

As for whether standards imposed on the professional should be higher or lower when the amateur cannot be assumed to infer or act correctly, this will be argued to depend on whether the amateur is more likely to act with too little or with too much care, as well as on whether care levels are substitutes or complements.

The model below will provide a way of structuring these issues.

First, the case of two-sided ignorance will be addressed briefly. The case, which seems important to consider, perhaps especially for the interactions that involve only non-professionals, is analytically simple, and can therefore be dealt with briefly. Second, one-sided legal ignorance will be analyzed.

\section{Two-sided legal ignorance}

If neither of the two parties knows the standards established by past court decisions, it is immediately clear that the standards will not affect behavior. 
Then, courts should, in the absence of risk allocation or fairness considerations (an important caveat), not hold the injurer liable or society should bar claims in the given area of activity. This will prevent costly future litigation that achieves nothing in terms of deterrence. By (unambiguously) not holding the injurer liable, future plaintiffs will be discouraged from filing suit.

\section{One-sided legal ignorance}

It will now be assumed that the professional party (henceforth $\mathrm{P}$ or she) will become informed about negligence standards, while the amateur (henceforth A or he) will not. To analyze how outcomes depend on the sequence of moves and on the degree of A's ignorance, a model is useful.

The Model and the Analysis

The overall game to be analyzed is the following:

1. Nature chooses the tort game played between $P$ and $A$,

2. The court chooses standards of care both for $P$ and for $A$,

3. P becomes informed about the game and its standards,

4. A does not become informed about the standards of negligence, but may or may not become informed about which game Nature has chosen, 
5. The parties choose their level of care, either sequentially or simultaneously, and

6. A loss may arise which is shared according to the liability rule.

The game played between $\mathrm{P}$ and $\mathrm{A}$ is one where they both affect the probability or the size of a loss that is born by the victim ${ }^{4}$. The parties are assumed to minimize their expected costs, i.e. they are risk neutral, and the court is assumed to minimize total expected costs. The equilibrium concept will in general be the perfect Bayesian Nash equilibrium. In the following, it will be assumed that $\mathrm{P}$ is the injurer. In a subsequent section, the case will be considered where $\mathrm{A}$ is the injurer and the loss falls on $\mathrm{P}$ and near the end, it will be analyzed whether strict liability is efficient under one sided legal ignorance.

Section 2 is organized as shown in Figure 1.

Figure 1.

${ }^{4}$ Thus, the setting will be that of accident law, but in part the analysis carries over to the tort/contract boundary. Note that in a contractual setting, the professional may be given an incentive to inform the amateur (in which case the present analysis applies to the two parties' care in sending and receiving the information). 


\begin{tabular}{|l|l|l|}
\hline & A knows the game & $\begin{array}{l}\text { A does not know the } \\
\text { game }\end{array}$ \\
\hline P does not act before A & section 2.1.1 & section 2.2.1 \\
\hline P acts before A & section 2.1.2 & section 2.2.2 \\
\hline
\end{tabular}

2.1. A knows the game

When $\mathrm{P}$ and $\mathrm{A}$ act simultaneously (or $\mathrm{A}$ acts before $\mathrm{P}$ ), $\mathrm{A}$ will not be able to infer anything from the behavior of $\mathrm{P}$. If $\mathrm{A}$ knows the game played, he may be able to infer the standards of negligence; these may follow naturally from the two parties' costs and the effectiveness of precaution. In that case, the court should naturally set the optimal standard at the first-best level, which is then also the level expected by $\mathrm{A}$ (and known to $\mathrm{P}$ ).

It seems, however, worth considering also the case where A knows the game with $\mathrm{P}$, but cannot infer standards of due care, perhaps because he does not know how such standards are set. Thus, in the next section, the case where A knows the game played with $\mathrm{P}$ but not the overall game with the court will be analyzed; first (in section 2.2.1) for the case when A cannot observe P's act, and then (in section 2.2.2) for when A can observe P's act. 
2.2.1 A knows the game with P but cannot infer standards; P does not act before $\mathrm{A}$

It will be assumed in this section that while A knows the pay-offs of the game with $\mathrm{P}$, he does not fully understand the overall game including the court, and has no way of inferring what the standards might be. Thus, it will be assumed that his beliefs are exogenous, i.e. formed by some thought process outside the model, and not by a rational consideration of the court's objectives. The question is whether A's ignorance may make it optimal for the court to depart from the first-best standards. The game shown in figure 2 can be used to analyze this question; first best standards are for $\mathrm{A}$ and not for $\mathrm{P}$ to take care and the question is whether the court should require care of $\mathrm{P}$ when $\mathrm{A}$ does not know the standards, in order to ensure that at least one of the two parties takes care. The figure indicates the size of the expected loss as a function of care levels.

Figure 2. Game $\alpha$ : A should take care and P should not

\begin{tabular}{|l|l|l|}
\hline P's care $\backslash$ A's care & No care & Care \\
\hline No care & 3 & $b$ \\
& & \\
\hline Care & $a$ & c \\
\hline
\end{tabular}


Assume that $1<c<b<a<2$, and that the cost of care equals 1 for both parties (This assumption concerning costs will be maintained throughout). This implies that the cost minimizing set of care levels is for $A$, but not for $P$, to take care. However, it will now be shown that if A does not realize this, but attaches a high enough probability $\chi$ to the standard being that $\mathrm{P}$ should take care it will be optimal for the court to require care by $\mathrm{P}$. This will be shown under the assumption that the parties split the loss when both are negligent under the rule of comparative negligence. Thus, consider the case where $\mathrm{A}$ acts first. If $A$ takes care, so will $P$, if care is required of $P$, for if $P$ takes care, she will not bear any liability but only the cost of precaution, while if she does not take care, she will incur the expected cost of $b$, and $b>1$. Hence, A's expected cost of taking care will be $1+c$, when care is required of P. If $\mathrm{A}$ does not take care, $\mathrm{P}$ will still take care under the assumption that comparative negligence implies equal sharing, since $\frac{3}{2}>1$. Hence, A's expected loss from not taking care will be $b$, which is less than $1+c$. Hence, A will not take care when he believes $\mathrm{P}$ is required to take care. On the other hand, it is clear that A will take care when he believes that care is not required of $P$, for if care is not required of $\mathrm{P}$, she will not take care and $3>b+1$. It follows that if $\chi$ is sufficiently high, A will not take care. It will then be optimal for the court to require that $\mathrm{P}$ takes due care. This illustrates that it may be optimal to adjust for A's ignorance of first-best standards by requiring a higher than optimal 
level from P. A similar argument can be made for the case where the two parties act simultaneously.

On the other hand, if $\chi$ is small, and $\mathrm{A}$ believes that he will be made to bear the loss himself, he will take care and it will then be optimal for the court not to require care of $\mathrm{P}$. Standards should then be set at the first best level. In the example, P's and A's care levels are substitutes and A takes less care than optimal, which shows that it may then be optimal to require more care by P than first-best. It is easily verified that if care levels are complements, as they may be when e.g. a seller provides information to a buyer and the buyer may spend more or less time studying the information, it is optimal to require less care of $\mathrm{P}$ than first-best, when $\mathrm{A}$ exercises less than optimal care. In addition, by the same logic, if $A$ exercises more than optimal care, the standard imposed on P will tend to be lower than first best when care levels are substitutes, and higher than first-best when care levels are complements ${ }^{5}$. In conclusion, when A does not know the standard, and cannot see P's act before acting himself, it may well be optimal for the court to set the standard for $\mathrm{P}$ either above or below the first-best level.

${ }^{5}$ See Lando (2006). 
2.2.2 A knows the game but cannot infer standards; $\mathrm{P}$ acts before $\mathrm{A}$

When P acts before A, A may be able to infer the standard set by the court from the act of $\mathrm{P}$. To illustrate, consider again game $\alpha$ above. If $\mathrm{P}$ acts with care, A should infer that the standard is for P to take care, since if the standard is for P not to take care, it will be optimal for her not to do so. A will then have optimal incentives, since if $\mathrm{P}$ is not negligent, $\mathrm{A}$ will bear his own loss. When $\mathrm{A}$ bears all risk, A will have optimal incentives given P's act. However, it may be argued that $\mathrm{P}$ will then have an incentive to delude $\mathrm{A}$ into believing that no care is required of her, when the opposite is the case, for that may induce $A$ into taking care. This issue of separating versus pooling perfect Bayesian Nashequilibrium will now be illustrated in game $\alpha$; there is an important reason why the negligence rule discourages this kind of misrepresentation. Thus, if in game $\alpha \mathrm{P}$ is successful in deluding $\mathrm{A}$ by acting without care and thereby inducing care by $A$ (which is optimal for $A$ if the standard for $P$ is not to take care), $\mathrm{P}$ will still be liable for the loss $b$. If A realizes his mistake concerning P's duty to exercise care after the loss (perhaps after consulting a lawyer), the cost to $\mathrm{P}$ will be $b>1$, while P's cost is only 1 of taking care, which will free her of all liability. Thus, due to the discontinuity of the negligence rule, there will be a tendency towards separating (informative) equilibria: $\mathrm{P}$ will act with care if required and without care if not required, and will not attempt to delude $A$. Given this tendency, it may well be best for the court to set negligence standards at the first-best level when P acts first and A knows the game. 
This ends the analysis of the case where A knows the game.

2.3 A does not know the game

2.3.1. A acts before or at the same time as $P$

When $\mathrm{A}$ does not know the game played with $\mathrm{P}$, the above results concerning the possible optimality of setting standards below or above first best levels when $\mathrm{P}$ acts before or at the same time as $\mathrm{A}$ apply a fortiori. The more interesting question is whether, when $\mathrm{A}$ does not know the game and $\mathrm{P}$ acts first, A can still infer something from P's act.

\subsection{1. $P$ acts before $A$}

It will now be argued, by example, that this depends on the degree of A's ignorance. Two examples will be contrasted. In the first example, A's ignorance is limited in the sense that his uncertainty only involves two games. He is uncertain whether game $\alpha$ or game $\beta$ is played. In the second example, he is uncertain whether game $\alpha, \beta$ or $\kappa$ is played, and it is shown that he cannot then infer the standard from P's act, and that it may then, again, be optimal for the court to depart from first best standards.

An example where A can infer the game and the standard from P's act 
Consider the situation where A does not know whether the game $\alpha$, introduced above, or the game $\beta$, illustrated in Figure 3 , is played. Assume, as above, that $1<c<b<a<2$. The two games are mirror images of each other. Since $1<c<b<a<2$, implying that $b+1<a+1<3<c+2$, only A should take care in game $\alpha$ and only $\mathrm{P}$ should take care in game $\beta$.

Figure 3.

Game $\beta$ : $\mathrm{P}$ should take care and $\mathrm{A}$ should not

\begin{tabular}{|l|l|l|}
\hline P's care $\backslash$ A's care & No care & care \\
\hline No care & 3 & $a$ \\
& & \\
\hline care & $b$ & c \\
\hline
\end{tabular}

Note that in game $\alpha$, where it is optimal for A but not for $\mathrm{P}$ to take care, it is better that $\mathrm{P}$ takes care than that no one takes care, since $a+1<3$. The converse is true for game $\beta$. 
It will now be shown that when $\mathrm{P}$ acts first, A can infer the game and the standard from the act by $\mathrm{P}$, and the court should therefore set the standards of negligence at the optimal levels. This means requiring care by $\mathrm{A}$ but not by $\mathrm{P}$ when Nature has chosen game $\alpha$, and requiring care by $\mathrm{P}$ but not by $\mathrm{A}$ when Nature has chosen game $\beta$.

The idea, which has already been alluded to for the case where A knows the game but not the standards, is that $A$ will infer that if $P$ acts without care this must be because care is not required of her, for if care were required of her, she would have an incentive to rid herself of all liability by exercising care. Hence, P's act will be informative of the standard, or, put differently, no pooling exists, only a separating (informative) equilibrium.

Lemma 1: When $\mathrm{P}$ acts first, and the game is either $\alpha$ or $\beta$, and $1<c<b<a<2$, no pooling Bayesian perfect Nash-equilibrium exists when comparative negligence involves an equal sharing of the loss.

Proof: A pooling equilibrium is characterized as follows. Whether the game played is $\alpha$ or $\beta, \mathrm{P}$ chooses no care ${ }^{6}$. A learns nothing from the act of $\mathrm{P}$ and behaves optimally given his prior belief concerning which game is played. In this pooling equilibrium, consider first the choice of $A$. There is no information

\footnotetext{
${ }^{6}$ No pooling equilibrium exists in which $\mathrm{P}$ chooses care when the standard is no care, since that is clearly not optimal for $\mathrm{P}$.
} 
in the act by P. This means that A's prior belief will be unchanged. Denote A's prior probability that game $\alpha$ is played by $r$, and assume that the standard applied to $\mathrm{P}$ is no care. A's expected cost from exercising no care when $\mathrm{P}$ also does not exercise care will be: $r \times 3+(1-r) 0=3 r$, while A's expected cost from care will be: $1+r b$. No care is optimal for A when $r<\frac{1}{(3-b)}$. This cannot be part of a pooling equilibrium, for a pooling equilibrium requires that it be optimal for P to act without care also when the standard is care. If the response by $A$, however, is to act with no care, both can be considered negligent, and if they share the loss of 3 equally according to the rule of comparative negligence, the pay-off to $\mathrm{P}$ would be higher if she acted with care, as that would only imply a loss of 1 in cost of care. This reflects the discontinuous nature of the negligence rule mentioned already; by living up to the standard, $\mathrm{P}$ can avoid liability altogether. If the response by $\mathrm{A}$ is to take care, as it will be when $r<\frac{1}{(3-b)}$, A will escape liability, but $\mathrm{P}$ will still be liable for the loss $b$. Since $b>1$, this is not optimal for $P$ when care is required of her. Hence, no pooling equilibrium exists. QED.

Thus, even if $\mathrm{P}$ succeeds in inducing high care by $\mathrm{A}$, there will still be a possibility of a loss, and for that loss, $\mathrm{P}$ will be fully liable. Hence, it is likely to be better for $\mathrm{P}$ to rid herself of all liability by taking a high level of care. Note that this logic does not apply in all circumstances. When A can eliminate all 
risk of a loss by taking care, it can be optimal for $\mathrm{P}$ to feign a low standard. This case is considered below, but before turning to this, it should be established that in the case under study, there exists a separating and fully revealing equilibrium where $\mathrm{P}$ acts with care when the game is $\beta$ and the standard is care and without care when the game is $\alpha$ and the standard is care:

Lemma 2: When $1<c<b<a<2$, a separating equilibrium exists.

Proof. Note first that when the standard for $\mathrm{P}$ is no care, it is optimal for $\mathrm{P}$ to act without care in which case it is optimal for A to respond with care, since when A believes that the standard is no care (for P), he must bear the loss, and $3<1+b$.

Second, note that in a separating equilibrium the act reveals the standard, and that when $\mathrm{P}$ acts with care it must be optimal for $\mathrm{A}$ to respond with no care. The latter follows from the fact that $c+1<a$, since when $\mathrm{P}$ acts with care and is hence not liable, A bears the loss, which is $c$, if he acts with care, and $a$ if he does not.

Third, note that when $\mathrm{A}$ responds to care by $\mathrm{P}$ by not taking care and would respond to no care by taking care, $\mathrm{P}$ will prefer to take care when the standard is care, since $b>1$ (where $b$ is the cost to $\mathrm{P}$ if she does not take care, but $\mathrm{A}$ does, and the standard is for P to take care; and where 1 is the cost of taking care, hence relieving herself of liability). QED. 
Thus, for the game considered, the only equilibrium is separating, hence the information will be revealed under the negligence rule, and it is optimal to set the standard at the first-best level, since $\mathrm{P}$ will reveal her information in equilibrium.

Thus, it has been established that in the specific example, when comparative negligence involves an equal sharing of the loss, and when $1<c<b<a<2$, the negligence standard should be set at the first-best level.

In conclusion, situations exist where A can infer the game and the standard from P's act, and where the court should set standards at the first-best level. The negligence standard provides the injurer an incentive to adhere to the standard; if the victim knows this, he may be able to infer the risk from the act of the injurer and react optimally, since the risk will be on him.

A counterexample where $\mathrm{P}$ can mislead A

As mentioned, one can conceive of circumstances where $\mathrm{P}$ can mislead A into believing that the standard of care is lower for $\mathrm{P}$ than it really is. This may occur e.g. when almost all risk is eliminated by A taking care. Consider the following game:

Figure 4: A counter-example 


\begin{tabular}{|l|l|l|}
\hline $\begin{array}{l}\text { Injurer's carelvictim's } \\
\text { care }\end{array}$ & 0 & 1 \\
\hline 0 & 3 & $e$ \\
\hline 1 & $d$ & $c$ \\
\hline
\end{tabular}

where $2+c>3>1+d>1+e$ and where $e<1$. The first best allocation is for A to take care and for $\mathrm{P}$ not to take care, but care by $\mathrm{P}$ is better than no care at all. Does a pooling equilibrium exist, where $\mathrm{P}$ chooses no care whether or not care is required of her or not? Consider such an equilibrium. A will infer nothing from the act of $\mathrm{P}$. His priors will remain unchanged. Assume that his prior beliefs are as given in Figure 5 below:

Figure 5: A's prior beliefs about standards

\begin{tabular}{|l|l|l|}
\hline & A should take care & A should not take care \\
\hline P should take care & $\lambda_{1}$ & $\lambda_{2}$ \\
\hline P should not take care & $\lambda_{3}$ & $\lambda_{4}$ \\
\hline
\end{tabular}

where $\sum_{i} \lambda_{i}=1 \lambda_{1}$.

A's expected cost from acting with care when observing no care by $P$ will be:

$1+\lambda_{1} 0+\lambda_{2} 0+\lambda_{3} \times e+\lambda_{4} \times e$ 
while A's expected cost from acting without care when observing no care by $P$ will be:

$\lambda_{1} \times \frac{3}{2}+\lambda_{2} \times 0+\lambda_{3} \times 3+\lambda_{4} \times 3$

A will not take care when:

$\lambda_{1} \times \frac{3}{2}+\lambda_{2} \times 0+\lambda_{3} \times 3+\lambda_{4} \times 3<1+\lambda_{1} 0+\lambda_{2} 0+\lambda_{3} \times e+\lambda_{4} \times e$

i.e. when $\lambda_{1} \times \frac{3}{2}+\lambda_{3} \times 3+\lambda_{4} \times 3<1+\lambda_{3} \times e+\lambda_{4} \times e$.

Note that $e<1$. Essentially, A will take care when $\lambda_{2}$ is small. Thus, a pooling equilibrium exists when $\lambda_{2}$ is small. When $\lambda_{2}$ is large, A will not take care and $P$ will suffer a loss of 3 when care is required of her and not of $A$; this is hence not an equilibrium.

In the pooling equilibrium, i.e. when $\lambda_{2}$ is small, $\mathrm{P}$ will respond to a standard of care by not taking care, and she will induce A to take care. Note, however, that this would also be the outcome if the standard for $\mathrm{P}$ is no care (when $\lambda_{2}$ is small). Hence, the fact that $P$ may attempt to mislead $A$ and may be successful in doing so for some prior beliefs by $\mathrm{A}$ does not provide a reason for the court to depart from the first best. For in departing from the first best, the court only creates the same outcome that $\mathrm{P}$ generates by deluding $\mathrm{A}$. 
In conclusion, situations exist where $\mathrm{P}$ can delude $\mathrm{A}$ into believing that no care is required of $\mathrm{P}$; such situations, however, do not provide a reason for the court to depart from first-best standards.

An example where A can infer neither the game nor the standard

In the example above, A's ignorance was limited; he knew that the game was either $\alpha$ or $\beta$. Naturally, it is likely to be more difficult to infer the game when A's ignorance is greater, as when A does not know which of several possible games is played. This can be shown by introducing a third game into the example above. Nature now chooses between the three games, $\alpha, \beta$ and $\gamma$. The court chooses the standards and P observes both the game and the standards while A observes nothing.

Assume that the game $\gamma$ is one where no risk is present:

Figure 6: Game $\gamma$ : The no-risk game

\begin{tabular}{|l|l|l|}
\hline P's care $\backslash A$ 's care & 0 & 1 \\
\hline 0 & 0 & 0 \\
\hline 1 & 0 & 0 \\
\hline
\end{tabular}


In the game $\gamma$, P will of course exercise no care, and when A observes no care by $P$, he may infer that this game is being played. Alternatively, he will at least update his belief to attach a greater probability to this game being played. Thus, consider the case where A attaches a prior probability of $r_{1}$ to the game $\alpha$, and a prior probability of $r_{2}$ to the game $\beta$; the probability of the game $\gamma$ is then $1-r_{1}-r_{2}$. It will now be shown that if $r_{3}>(2-a) r_{1}$, the equilibrium is:

For the court to:

Require care by $\mathrm{P}$ and not by $\mathrm{A}$ in game $\alpha$,

Require care by $\mathrm{P}$ and not by $\mathrm{A}$ in game $\beta$,

Require no care by $\mathrm{A}$ and no care by $\mathrm{P}$.

For $\mathrm{P}$ to:

Take care in game $\alpha$ and game $\beta$, Not take care in game $\gamma$.

For A to: Not take care.

Proof: See Appendix. 
The example illustrates that A may not know the size of the risk and what is required of him from observing what is required of $\mathrm{P}$ (through observing P's act). If $A$ is mistaken concerning the size of the risk, he may choose the wrong level of care, and it may then be optimal for the court to have P take precautions even though it would be better if $A$ did.

3. The professional party is the victim

It has been assumed so far that $A$ bears the loss, and that if $P$ is not negligent, the loss remains with A regardless of A's level of care. However, in some cases, the loss falls on $\mathrm{P}$ rather than $\mathrm{A}$ and $\mathrm{P}$ will bear it unless $\mathrm{A}$ acts negligently. For example, if $A$ is an insurance customer who fills in a questionnaire and $\mathrm{P}$ is the insurance company that formulates the questionnaire, and A does not mention a particular factor that increases his risk, $\mathrm{P}$ bears the loss unless $\mathrm{A}$ is found negligent. The main difference concerns the discontinuity of the loss function when $\mathrm{P}$ takes care; when $\mathrm{P}$ is the victim, her loss remains when A also takes care.

Consider again the two games $\alpha$ and $\beta$, and assume that $\mathrm{P}$ acts first. Recall that: $1<c<b<a<2$.

Figure 2. Game $\alpha$ : A should take care and P should not 


\begin{tabular}{|l|l|l|}
\hline P's care $\backslash$ A's care & No care & care \\
\hline No care & 3 & $b$ \\
& & \\
\hline care & $a$ & c \\
\hline
\end{tabular}

Game $\beta$ : P should take care and A should not

\begin{tabular}{|l|l|l|}
\hline P's care $\backslash$ A's care & No care & care \\
\hline No care & 3 & $a$ \\
& & \\
\hline care & $b$ & c \\
\hline
\end{tabular}

Note that the separating equilibrium, where $\mathrm{P}$ takes care in game $\beta$ but not in game $\alpha$ and where A responds by taking care in game $\alpha$ but not in game $\beta$, breaks down. For if $A$ responds with care to no care by $\mathrm{P}$, no care is better than care for $\mathrm{P}$ in game $\beta$, since $1+c>a$. When the separating equilibrium breaks down, the pooling equilibrium will be one where $\mathrm{P}$ does not take care in any of the two games. A's choice of whether or not to take care will then depend on A's prior probabilities concerning which game is played and which standard applies. It may then become optimal for the court to depart from first-best standards. Thus, assume that $\mathrm{A}$ considers game $\beta$ to be very likely, and that 
the likelihood that he will not be held liable in this game to be high. The following is then an equilibrium: The court does not require care by $A$ in any of the games, but requires care by $\mathrm{P}$ in both games. $\mathrm{P}$ will take care in both games, and A will never take care. To verify: When A observes care by $\mathrm{P}$, this is non-informative and $\mathrm{P}$ takes care in both games. A will then react with no care if he believes the likelihood of game $\beta$ to be high. This creates a firstbest outcome in game $\beta$ and a 'second-best' outcome in game $\alpha$, which is the best that can be achieved given the absence of separating equilibria and given A's beliefs, which make him not take care in a pooling equilibrium. In conclusion, separating (informative) equilibria, where $\mathrm{P}$ acts first and $\mathrm{A}$ infers the game and the standard from P's act, are less likely when P is the victim (since the discontinuity of the negligence standard for the injurer provides an incentive for separation). Therefore, it is more likely to be optimal for the court to depart from first-best standards when $\mathrm{P}$ is the victim than when $\mathrm{P}$ is the injurer.

\section{Strict liability}

If $\mathrm{P}$ is a long run player who takes part in many interactions, she may well be assumed to know how $A$ reacts to her acts. Assume, then, that $P$ knows A's response-function. It may then be thought that strict liability will be optimal given A's response-function (which by assumption is independent of the rule 
stipulated by the court ${ }^{7}$ ). However, this is not true. To see why not, denote P's act by $p, \mathrm{~A}^{\prime} \mathrm{s}$ response by $a(p)$ and the total expected costs by $T(p, a(p))$. These total costs include A's cost of care, but these are not part of the damages. Hence, $\mathrm{P}$ will disregard A's cost of care when choosing $p$; P will minimize only total losses from the accident plus her own cost of care. Onesided legal ignorance hence does not provide a clear rationale for strict liability. On the other hand, if the act $a$ does not depend on $p$, as when A acts first or as when they act simultaneously, or if the dependence is of small significance, strict liability will be optimal and will take advantage of the fact that $P$ is likely to know A's act (or the distribution of different acts by different types of A's) better than the court.

5. An application of the analysis

The example mentioned in the Introduction of the fraudulent investment project may illustrate. The bank did not warn the amateur investors that it had not investigated the project, while the investors failed to seek professional advice and to otherwise take precautions. In this case, $\mathrm{P}$ is the injurer and $\mathrm{A}$ cannot infer the risk from the act of $\mathrm{P}$. When $\mathrm{P}$ says nothing, it may be because

${ }^{7}$ The assumption is hence that A not only does not know the negligence standard, he does not know the rule either (whether it is strict liability or negligence, e.g.). 
it is not required of $\mathrm{P}$ to say anything or it may be because there is no risk. A cannot infer which is the case and in fact (allegedly) infers incorrectly.

Thus, the part of the analysis which applies is that where $\mathrm{P}$ acts first but where P's act is not informative. The analysis holds that the care required of P should be above first-best when $\mathrm{P}$ is more reachable than $\mathrm{A}$, when $\mathrm{A}$ may take less than optimal care when not informed of the standards and of the risk, and when care levels are substitutes. These assumptions are all fulfilled, and the analysis hence casts doubt on the correctness of the verdict not to hold the bank liable ${ }^{8}$.

6. Remarks

The analysis calls for some additional remarks.

First, when A does not know the standards, his ignorance may induce him to act with caution, if he is risk averse. Conceivably, A's ignorance may lead him to take too much care, in which case it may be optimal to require less than first best care by $P$ when care levels are substitutes. But naturally, A's mistake may lie in the belief that the risk is small or non-existent, and so the case

${ }^{8}$ Perhaps the Court reasoned that if amateur investors can be induced to seek professional advice, optimal levels of precaution can be realized since the professionals will know standards of care. 
analyzed above where A may act with suboptimal care is also worth considering.

Second, it is worth stressing that P may be required to inform A of what is required of $A$. For example, in the area of product liability, the producer is often required to instruct the consumer how to handle a product correctly. As another example, an insurance company may inform its customers what level of detail and precision is required of them in filling out questionnaires. When communication costs are low, this may alleviate the problem of amateur ignorance.

Third, A may not know that he can make a claim against $\mathrm{P}$, and may never find out. Contacting a lawyer is expensive and so is litigation. Knowing this ex-ante may lead A (as a victim) to take care, perhaps excessively. In such a setting it will tend to be optimal (when care levels are substitutes) to set the standard for $\mathrm{P}$ below first best, not only because $\mathrm{A}$ will tend to take care but also because the standard will anyway be unlikely to affect P's behavior (who does not have to fear the bringing of suit). Setting a high standard may create occasional court cases that do serve no purpose when $\mathrm{P}$ is not be affected.

\section{Summary}

When two parties both affect an expected loss by their acts and only one of them has the incentive (as a long run player) to become informed about the standard of care, the court should generally take into consideration the fact 
that it can affect the behavior of the informed party more easily than that of the uninformed. However, when the informed party acts first, she may by her act inform the ignorant party of the risk involved and of standard applied by the court. The negligence rule is well suited for this kind of information transmission, since it generally discourages the attempt by the informed party to deceive the uninformed party, i.e. the discontinuous loss from acting below standard tends to make it optimal for the knowledgeable party to live up to the standard of care, in which case the act performed becomes informative of the standard of care. However, the extent to which A is likely to draw correct inferences concerning the standard of negligence from the act of $\mathrm{P}$ depends on A's knowledge of the situation. If e.g. A is ignorant of the size of the risk, his inference and response may be inadequate, and it may then not be optimal to set the standard of care for $\mathrm{P}$ at the first-best level. It then becomes important whether A is likely to take too much precaution or too little and whether care levels are substitutes or complements. When care levels are substitutes and A is likely to under-estimate the risk, it may be better to require care by the knowledgeable party to ensure that at least one of the parties takes care. These latter considerations are more likely to be decisive when the informed party is the victim than when she is the injurer, since the discontinuity of the negligence rule mentioned above does not apply to the victim, but only to the injurer, and may therefore be more difficult to draw inferences from the act of the informed party when she is the victim. 
Strict liability on the knowledgeable party may well be optimal under one-side legal ignorance, since it takes advantage of the P's potentially superior knowledge concerning A's beliefs, but when P acts first and can influence A's act, her incentives will not always be optimal, since she will not take A's cost of care into account.

\section{Appendix}

Proof that if $r_{3}>(2-a) r_{1}$, the equilibrium is:

For the court to:

Require care by $\mathrm{P}$ and not by $\mathrm{A}$ in game $\alpha$,

Require care by $\mathrm{P}$ and not by $\mathrm{A}$ in game $\beta$,

Require no care by $\mathrm{A}$ and no care by $\mathrm{P}$.

For $\mathrm{P}$ to:

Take care in game $\alpha$ and game $\beta$, Not take care in game $\gamma$.

For A to: Not take care. 
To show that the strategies are optimal, it must be shown that:

$\mathrm{P}$ and $\mathrm{A}$ act optimally given the decision by the court, The court acts optimally.

1. Optimal responses to the act by the court:

P must consider that regardless of her act of care, A will not take care. Then, when the court requires care by $\mathrm{P}$ in game $\alpha$, it will be optimal for $\mathrm{P}$ to take care. She will otherwise be held liable for the loss of 3 (and there will be no issue of comparative negligence, since the court does not require care by A). Similarly, when the court requires care by $\mathrm{P}$ in game $\beta$, it will be optimal for $\mathrm{P}$ to exercise care in game $\beta$. If no care is required by $\mathrm{P}$ in game $\gamma$, it will be optimal for P not to exercise care (since she will not be held liable). Thus, P's strategy is optimal given A's. Given P's strategy, A will react optimally by not taking care in game $\alpha$, since $\mathrm{b}+1>\mathrm{c}$. He will realize that he will bear the loss, but the loss will be too small for it to be optimal to take precautions against it. Likewise, A will react optimally by not taking care in game $\beta$, since $a+1>c$. Since A should of course not take care in game $\gamma$, it is optimal for A never to exercise care.

2. The optimality of the court's strategy 
The court realizes first best except in game $\alpha$, where A should take care. The court should consider requiring care of $\mathrm{A}$ and not of $\mathrm{P}$ in game $\alpha$. If the court did so, would the outcome be superior? Consider how $\mathrm{P}$ would react to this out-of-equilibrium move by the court. $\mathrm{P}$ will react by not taking care since it is not required of her. A will react by not taking care, since this is A's equilibrium strategy. Hence, loss 3 will be incurred, which is not an improvement for the court. Thus, the strategies form an equilibrium.

What is more, when $r_{3}>(2-a) r_{1}$, an equilibrium does not exist where the court requires care by $\mathrm{P}$ in game $\beta$ only, and not in game $\alpha$ and $\gamma$. In such an equilibrium, A will anticipate this strategy by the court and will realize that $P$ will then take care only in game $\beta$ (since $\mathrm{P}$ will not take care when it is not required of her). Let A's prior probabilities of the three games be $r_{1}, r_{2}$ and $r_{3}$. If A observes no care by $\mathrm{P}$, he will update his belief about the game according to Bayes' rule. Hence, when observing no care, he will realize that either game $\alpha$ or game $\gamma$ is played (correctly anticipating the strategy chosen by the court and the response by $\mathrm{P}$ ). The probability of game $\alpha$ will then be $\frac{r_{1}}{r_{1}+r_{3}}$, while the probability of game $\gamma$ will be $\frac{r_{3}}{r_{1}+r_{3}}$. It will then be optimal for A to choose 
no care if the latter is large. More precisely, no care entails the cost: $\frac{r_{1}}{r_{1}+r_{3}} 3+$ $\frac{r_{3}}{r_{1}+r_{3}} 0$, while care costs $\frac{r_{1}}{r_{1}+r_{3}} a+1$. No care is optimal when $1>$ $\frac{r_{1}}{r_{1}+r_{3}}(3-a)$, i.e. when $r_{3}>(2-a) r_{1}$. Thus, when this is the case, A will exercise no care when P exercises no care; A will mistake the size of the risk. However, when this is the case, the outcome is not an equilibrium. It would be better for the court to require care by $\mathrm{P}$ in game $\alpha$. If the court did so, and hence departed from the equilibrium strategy, and $\mathrm{P}$ acted with care in game $\alpha$, A would interpret this to mean that the game being played is $\beta$, since in equilibrium this is the only game where $\mathrm{P}$ acts with care. In game $\beta$, if $\mathrm{P}$ acts with care, it will not be optimal for A to act with care. When A responds to P's care by not taking care in game $\alpha$, there will be a total loss which is smaller than the loss which arises in equilibrium in game $\alpha$, namely 3 (since neither $\mathrm{P}$ nor A takes care). Thus, the court can do better by departing from its strategy, which was hence not an equilibrium strategy. It can be verified quickly that no other candidates exist for equilibrium strategies by the court, and hence the only equilibrium is the one presented. QED. 
References

Craswell R. and Calfee C., 1986. Deterrence and Uncertain Legal Standards, J Law Econ Organ. 2: 279-303.

Lando, Henrik., 2006. Optimal Negligence Standards When One Party Is Ignorant of the Standards, forthcoming in Research in Law and Economics.

Shavell, Steven., 1987. Economic Analysis of Accident Law, Harvard University Press, Cambridge, MA.

Verkerke, J.H., 2003. Legal I gnorance and Information-Forcing Rules. Univ. of Virginia Law \& Econ Research Paper No. 03-4. http://ssrn.com/abstract=405560. 